\title{
Percepções acerca da atividade exportadora: 0 caso das empresas do APL de utensílios domésticos em alumínio do Sudoeste do Paraná*
}

\author{
Edson Santos Melo ${ }^{1}$ \\ Tatiane Beluzzo ${ }^{2}$ \\ Marcos Junior Marini ${ }^{3}$
}

\begin{abstract}
Resumo
O Arranjo Produtivo Local de Utensílios Domésticos em Alumínio do Sudoeste do Paraná é um dos mais tradicionais e importantes arranjos produtivos do estado. Desse modo, o presente estudo objetivou compreender, na visão dos empresários do referido APL, quais os desafios enfrentados para sua inserção no comércio exterior, considerando o ano de 2019 como período de análise. Como procedimento metodológico, adotou-se uma análise descritiva, associada a um levantamento de dados primários, sendo esse realizado por meio de um formulário estruturado, o qual foi aplicado em 24 empresas associadas ao referido APL. Os resultados demonstraram que $87,5 \%$ das empresas nunca exportaram. Mesmo entre as empresas que exportam, os resultados indicaram haver um desconhecimento dos benefícios advindos de tal atividade. Entretanto, a maioria dos participantes possuía percepção positiva com relação à exportação e, também, sobre as vantagens advindas por participarem do APL.
\end{abstract}

Palavras-chaves: Exportação. Utensílios domésticos em alumínio. Arranjo Produtivo Local. Sudoeste do Paraná.

\section{Perceptions about export activity: the cluster case of the companies of household utensils in aluminum from the Southwest of Paraná}

\begin{abstract}
The local productive arrangement of household utensils in aluminum in the Southwest of Parana is one of the most traditional and important productive arrangements in this state. Thus, this study aimed to understand, in the view of the cluster referenced entrepreneurs, the challenges faced for their insertion in foreign trade, considering the year 2019 as a period of analysis. As methodological procedure, a descriptive analysis was adopted, associated with a survey of primary data, which was carried out through a structured form applied in 24 companies associated with the referred arrangement. The results showed that $87.5 \%$ of the companies never exported. Even among companies that export, the results indicated that there is a lack of knowledge of the benefits arising from such activity. However, most of the participants had a positive perception in relation to exports and, also, of the advantages that come from participating in the cluster.
\end{abstract}

Keywords: Export. Aluminum household items. Cluster. Southwest Paraná.

\section{Introdução}

Toda discussão acerca do desenvolvimento econômico local se tornou um campo de estudo sistêmico, multifacetado e multidimensional. Dentre as muitas variáveis que podem

\footnotetext{
*Este artigo foi avaliado e apresentado no evento II-SLAEDR/VI-SIDER/III-SIDETEG, da UNIJUÍ, e indicado e aceito para ser publicado nesta revista pelo sistema Fast-Track.

${ }^{1}$ Doutorando no Programa de Pós-Graduação em Desenvolvimento Regional da Universidade Tecnológica Federal do Paraná. Professor da Universidade Estadual do Oeste do Paraná. https://orcid.org/0000-0001-5515-5323 Email: edson.melo@unioeste.br

${ }^{2}$ Economista (UEOP). https://orcid.org/0000-0003-0573-1278 Email: tati.fundicaojb@hotmail.com

${ }^{3}$ Doutorado em Tecnologia e Desenvolvimento. Professor no Programa de Pós-Graduação em Desenvolvimento Regional da Universidade Tecnológica Federal do Paraná. http://orcid.org/0000-0003-2539-0335

Email: marini@utfpr.edu.br
} 
contribuir para o crescimento e o desenvolvimento econômico de uma região, destacam-se o nível de atividade industrial e de serviços, não ficando os mesmos restritos somente à localidade que estão instalados ou presentes. Nesse aspecto, para Willers (2016), o êxito de qualquer estratégia de desenvolvimento econômico local depende, fortemente, da sintonia gerada entre as potencialidades locais, combinada à competitividade em mercados globais. Portanto, não se pode negligenciar os impactos da globalização sobre a economia e as comunidades locais.

De acordo com Alves (2016), a exportação, muitas vezes, é o ponto de partida necessário e universal no desenvolvimento das regiões. Ademais, ainda conforme o referido autor, o setor exportador é capaz de gerar efeitos multiplicadores, os quais podem provocar impactos positivos nas demais atividades econômicas, contribuindo, assim, para a internalização da renda gerada pelo setor exportador.

Conforme dados do Ministério da Economia (2020), no ano de 2019, somando a participação de todos os produtos, o estado do Paraná obteve uma receita superior a 16 bilhões de dólares com exportações, sendo $73,3 \%$ desse valor provenientes da indústria de transformação. Contudo, apesar dessa porcentagem estadual parecer elevada, estatísticas da Confederação Nacional das Indústrias (2019) demonstram que a participação nacional da indústria de transformação na exportação mundial representa apenas 0,90\%.

Nesse contexto, ressalta-se a importância da articulação de agentes territoriais visando à realização de ações conjuntas, tornando-se, assim um importante mecanismo de concentração espacial de empresas e culminando na promoção do desenvolvimento. Dessa forma, encontrados na forma de aglomerações empresariais e institucionais, os Arranjos Produtivos Locais (APLs) possuem como característica essencial a capacidade de gerar externalidades, as quais contribuem para o incremento da competitividade das empresas e, em consequência, do sistema ou arranjo local como um todo. Muito disso advém da maior facilidade de acesso à matéria-prima, mão de obra qualificada e de ações conjuntas, as quais acabam aumentando a competitividade das empresas locais. Além disso, pode-se até verificar a criação de consórcios direcionados à exportação. Em que pese as vantagens acima, observa-se no APL uma materialização de eficiência coletiva, em comparação a empresas que atuam isoladamente no mercado (SUZIGAN et al., 2004; SUZIGAN, 2006; VIGNANDI, CAMPOS e PARRÉ, 2013; MARINI e SILVA, 2014; MATTEI, MORAES e BEZERRA, 2017). Não por menos, de forma análoga, a Federação das Indústrias do Paraná (FIEP, 2019) ratifica que o cenário formado por um APL é extremamente positivo às empresas, e reforça sua importância, inclusive para a inserção dos participantes em novos mercados, incluindo aqui o mercado externo. 
Diante do exposto, emerge o seguinte problema a ser investigado: qual a percepção das empresas pertencentes ao APL de Utensílios Domésticos em Alumínio do Sudoeste do Paraná com relação ao mercado externo? Portanto, direciona-se como objetivo principal, compreender, na visão dos empresários do APL de Utensílios Domésticos em Alumínio do Sudoeste do Paraná, os desafios de se inserirem no comércio exterior, considerando o ano de 2019 como período de estudo. Verifica-se na literatura alguns estudos sobre o referido APL, sendo que eles abordam os mais variados aspectos, podendo-se citar Luciane, Ceretta e Rocha (2014), Vasco et al. (2014), Ceretta, Cunha e Rocha (2015), Poletto (2017) e Viera, Costa e Lima (2018). Porém, notou-se uma lacuna diante da temática proposta pelo presente estudo.

Em complemento, deve-se ponderar que a primeira empresa do ramo de fabricação de utensílio doméstico em alumínio se instalou na região sudoeste do Paraná ainda na década de 1980. Todavia, o referido APL somente iniciou suas atividades conjuntas algumas décadas depois, no ano de 2008. Já um estudo realizado pelo Instituto Paranaense de Desenvolvimento Econômico e Social (2006) identificou o setor de fabricação de artigos em metal para uso doméstico como um vetor de desenvolvimento local, principalmente concentrado na microrregião de Francisco Beltrão. Além disso, desde o ano de 2014, conforme o Plano de Desenvolvimento Regional Integrado elaborado pela Agência de Desenvolvimento Regional do Sudoeste do Paraná (2015), o setor de artigos metálicos de uso doméstico foi mapeado como uma entre as oito principais cadeias produtivas propulsivas locais, sendo, portanto, um setor estratégico. Por fim, atualmente, considera-se que exista na região a maior concentração de indústrias de alumínio do estado do Paraná e, também, o segundo maior polo deste setor no país (GOVERNO DO ESTADO DO PARANÁ, 2015; PEGORARO, 2019).

\section{Aglomerados produtivos}

A discussão sobre os aglomerados industriais já é algo consolidado na literatura, perpassando distintas escolas de pensamento. Adota-se como seu marco inicial a obra seminal de Marshall, publicada ainda em 1890, em que se discorreu a experiência dos distritos industriais da Inglaterra no século XIX e demonstrou-se que as economias externas advindas da aglomeração propiciavam certos benefícios às empresas (MARSHALL, 1996).

Desde então, entenderam-se três pontos essenciais capazes de fomentar a geração de economias externas, advindas não só da aglomeração de agentes produtivos, mas, também, da especialização destes, sendo eles: i) ocorrência de mão de obra especializada; ii) atração de 
fornecedores especializados pra suprimento da cadeia local de produção; e, iii) o efeito de transbordamento local (spill-overs), ou seja, a facilitação na difusão do conhecimento, habilidades e informações no ramo de atividade (SUZIGAN et al., 2004; GARCIA, 2006; SUZIGAN, 2006).

Transcorridas algumas décadas, mais pontualmente nos anos de 1970, boa parte das ideias de Marshall foram retomadas com o advento dos distritos industriais italianos (BECATTINI, 1991; AMARAL FILHO, 2001). Contudo, como destacado por Suzigan (2006), embora essenciais para explicar a origem dos distritos, as economias externas marshallianas não foram suficientes para entender seu desenvolvimento. Já nas décadas seguintes, 1980 e 1990, mesmo diante do processo de globalização e da acentuação nas assimetrias regionais, verificou-se, nos distritos italianos, grandes ganhos competitivos, corroborados pelo crescimento das exportações e da capacidade de inovação, o que foi atribuído à mudança na característica estrutural, transformando-os em sistemas de produção (SANTOS, DINIZ e BARBOSA, 2004; SUZIGAN, 2006; COSTA, 2011).

Foi nesse mesmo período apresentado anteriormente que novas matrizes teóricas se propuseram ao desenvolvimento de arcabouços analíticos em substituição às teorias de cunho regional das décadas de 1950 e 1960, muitas dessas, centradas ainda nos polos de crescimento industrial. Com isso, redirecionou-se o debate para as questões atinentes ao desenvolvimento endógeno e, de certo modo, ressignificou o debate das aglomerações produtivas, conforme resumido no Quadro 1 (MARINI et al. 2012; COSTA, 2014).

Do quadro 1, se faz oportuno ainda falar sobre dois autores que deram contribuições importantes em escolas distintas, sendo eles Paul Krugman, expoente da Nova Geografia Econômica, e Michael Porter, da Escola de Harvard.

Krugman $(1991 ; 1995 ; 1998)$ observou algumas forças que poderiam incentivar ou não uma aglomeração industrial, as quais ele chamou de forças centrípetas e centrífugas, além de incorporar na discussão a configuração do comércio internacional.

Com relação às centrípetas, o autor relaciona-as diretamente às externalidades marshallinas (efeitos do tamanho do mercado, mercados de trabalho densos e economias externas puras), além de adicionar a tese dos retornos crescentes. Já como forças centrífugas, relaciona-se fatores imóveis, aluguel das terras e deseconomias externas puras. Garcia $(2006$, p. 309) sintetiza a análise:

(...) existem também forças centrífugas, de repulsão, que desestimulam a concentração das empresas e as afastam da região. Quando as forças centrífugas superam as centrípetas, há uma tendência à expulsão de atividades econômicas e de 
empreendimentos industriais, como é o caso de diversas regiões metropolitanas em todo o mundo. Isso significa que há um limite superior para a extração das externalidades positivas, a partir do reconhecimento da existência de forças que desestimulam a concentração. Nesses casos, o autor aponta a importância das deseconomias de aglomeração, como os elevados custos de transporte, o preço e o aluguel de imóveis, dentre outros fatores que contribuem para o desestímulo à manutenção do nível de atividade econômica.

Portanto, para Krugman, a existência de condições favoráveis em termos dos retornos crescentes de escala é capaz de intensificar e reforçar a concentração de empresas, em que as forças centrípetas se apresentam com grande intensidade. Isso tende, além de aprofundar a concentração local de empresas, a aumentar a competitividade do sistema, já que as condições que geram os retornos crescentes também tendem a ser intensificadas.

Quadro 1 - Matrizes teóricas do desenvolvimento endógeno e as aglomerações produtivas

\begin{tabular}{|l|l|}
\hline Corrente Teórica & Principais características \\
\hline \multirow{3}{*}{ Teoria Neo-schumpeteriana } & $\begin{array}{l}\text { A inovação tecnológica implica no desenvolvimento } \\
\text { econômico, considerando a importância } \\
\text { dos spillovers (transbordamentos) de conhecimento. } \\
\text { Surgem os Sistemas Nacionais e Locais de Inovação. }\end{array}$ \\
\hline \multirow{3}{*}{ Teoria da Nova Geografia Econômica Industriais Italianos } & $\begin{array}{l}\text { Aglomerações produtivas tradicionais de pequenas e médias } \\
\text { empresas localizadas na chamada "Terceira Itália". } \\
\text { Valorização do território pelo conjunto social nele localizado. }\end{array}$ \\
\hline Teoria da Escola de Harvard & $\begin{array}{l}\text { Análise econômica da estrutura espacial da economia por } \\
\text { meio de forças centrífugas e centrípetas dos locais } \\
\text { produtivos. }\end{array}$ \\
\hline & $\begin{array}{l}\text { Teoria do Diamante. Vantagem competitiva: as } \\
\text { concentrações geográficas de empresas (clusters) ganham } \\
\text { importância por apresentarem vantagens competitivas } \\
\text { locais. }\end{array}$ \\
\hline
\end{tabular}

Fonte: adaptado de Marini et al. (2012).

Já Porter (1998) contribuiu imensamente ao inserir na literatura o conceito e o entendimento sobre os clusters, que ele mesmo define como sendo

(...) concentrações geográficas de empresas e instituições interconectadas em um determinado campo. Os clusters englobam uma variedade de setores vinculados e outras entidades importantes para a concorrência. Eles incluem, por exemplo, fornecedores de insumos, como componentes, máquinas e serviços, e fornecedores de infraestrutura especializada. Os clusters também costumam alinhar táticas para canais e clientes e, lateralmente, para fabricantes de produtos complementares e para empresas em setores relacionados por habilidades, tecnologias ou ambos. Finalmente, muitos clusters incluem instituições governamentais e outras - como universidades, agências, think tanks, provedores de treinamento e associações comerciais - que fornecem treinamento especializado, educação, informação, pesquisa e suporte técnico (PORTER, 1998, p. 78, tradução nossa). 
De acordo com Porter (1998, p. 80), os clusters podem afetar a concorrência de três maneiras: i) aumentando a produtividade das empresas com sede na área; ii) ditando a direção e ritmo de inovação, que sustenta o futuro crescimento da produtividade; e iii) estimulando a formação de novos negócios, que se expandem e fortalecem o próprio cluster.

Dessa forma, é nítido o fato que, no ambiente de um cluster, conforme apresentado, o principal ator não se resume apenas às empresas que ali se aglomeram, mas, sim, a uma complexa rede de múltiplos atores envolvendo relações que entrelaçam várias dimensões, podendo-se listar desde as relações básicas da empresa com o cliente, até outras de mensuração mais complicada, como o envolvimento de instituições de pesquisa, ensino, agentes de apoio e governança local $^{1}$ (SUZIGAN, 2006; GARCIA, 2006; CUNHA e TERRA, 2008; MARINI e SILVA, 2014; TORRE e ZIMMERMANN, 2015).

Diante das especificidades descritas anteriormente e outras particularidades locais, então, desenvolveu-se no Brasil, na década de 1990, o conceito de arranjo produtivo local (APL) o qual foi muito útil por nortear políticas públicas focadas em apoiar o desenvolvimento das aglomerações produtivas e industriais (SANTOS, DINIZ e BARBOSA, 2004; COSTA, 2014).

Devido à vasta literatura nacional cuja abordagem remete aos APLs, torna-se tarefa complexa optar por uma conceitualização única do termo. Não obstante, Cassiolato e Lastres (2003) conceituam APL em:

\begin{abstract}
Aglomerados territoriais de agentes econômicos, políticos e sociais, com foco em um conjunto específico de atividades econômicas, que apresentam vínculos mesmo que incipientes. Geralmente envolvem a participação e a interação de empresas, que podem ser desde produtoras de bens e serviços finais até fornecedoras de insumos e equipamentos, prestadoras e consultoria e serviços, comercializadoras, clientes e outros, e suas variadas formas de representação e associação. Incluem também diversas outras instituições públicas e privadas voltadas para: formação e capacitação de recursos humanos (como escolas técnicas e universidades); pesquisa, desenvolvimento e engenharia; política, promoção e financiamento. (CASSIOLATO e LASTRES, 2003, p. 27)
\end{abstract}

\footnotetext{
${ }^{1}$ Contudo, para Porter (1998, p. 86), os clusters não são uma estrutura presente nos países em desenvolvimento, sendo características de tais países a competição no mercado com abundância de mão de obra barata e recursos naturais. Assim, promover a formação de clusters em economias em desenvolvimento significa começar pelo nível mais básico: melhorar níveis de educação e qualificação, capacitação em tecnologia, abertura do acesso aos mercados de capitais e melhoria das instituições, etc. Em complemento, Schmitz e Nadvi (1999) argumentam que, nesse cenário, o cluster torna-se significativo porque facilita a especialização e o investimento eficaz em pequenas degraus.

${ }^{2}$ Conforme Cunha e Terra (2008, p. 11), uma conceituação como é o APL deve conter as especificidades locais, mesmo porque clusters e APLs, "apesar de parecerem semelhantes em um primeiro momento, não são inteiramente iguais, não possuem a mesma natureza e nem a mesma essência". Porém, segundo Debortoli et al. (2020), encontrase na literatura muitas definições para o mesmo objeto, sendo as mais comuns arranjo produtivo local, sistema produtivo local ou mesmo cluster.
} 
Já para Marini et al. (2012), o APL é uma aglomeração territorial de pequenas e médias empresas do mesmo setor ou correlatas, as quais buscam vantagens competitivas e eficiência coletiva por meio das externalidades e ações conjuntas desenvolvidas com os agentes econômicos, sociais e políticas que estão presentes nesse território. Entre os dois conceitos, observam-se algumas complementações. Em primeiro lugar, destaca-se que, enquanto forma de organização espacial, o APL permite estabelecer uma ponte entre o território e as atividades econômicas, implicando em condições favoráveis ao desenvolvimento local ou regional (SCHLEMPER, MARINI E BERNARTT, 2016; MATOS, CASSIOLATO e PEIXOTO 2017).

Outro aspecto é sobre a figura das pequenas e médias empresas. Segundo Suzigan et al. (2004), em APLs, apesar da presença de empresas de portes variados, o comum é um expressivo número de pequenas e médias empresas não integradas verticalmente. Tal notação é relevante, pois, como destacam Santos, Diniz e Barbosa (2004), o conceito de APL, tradicionalmente, tem como catalisador mais destacado, a importância da cooperação e, como característica fundamental, a presença de pequenas ou médias empresas concentradas espacialmente em alguns dos elos de uma cadeia produtiva.

\begin{abstract}
Geralmente, são as pequenas e médias empresas que mais dependem da localização, porque: a) têm mais dificuldade em abrir escritórios ou filiais em muitos lugares; $b$ ) possuem dificuldade de se relocalizar por uma questão de custos de investimento; c) o dono geralmente precisa estar presente e relocalizá-lo pode até ser mais difícil que relocalizar a empresa; e, por último, d) dependem muito das relações que têm no local, pois não possuem capital suficiente para obter certas escalas mínimas necessárias para se suprir de determinados serviços e externalidades que encontram em condições facilitadas e seguras no local atual e podem não encontrar em outros locais (SANTOS, DINIZ e BARBOSA, 2004, p. 163).
\end{abstract}

Em que pese tais condições, segundo Tatsch, Botelho e Matos (2017, p. 375), "com a definição da Política Industrial, Tecnológica e de Comércio Exterior em 2003, o governo federal altera a situação vigente em relação ao reconhecimento da importância de ações de apoio ao setor produtivo e inclui, nesse documento, o apoio aos APLs" ${ }^{3 \prime}$. Desse modo, Simonetti e Kamimura (2017) destacam algumas ações que visam ampliar as exportações dos APLs, como os Programas de Exportação de Consórcio, cujo objetivo centra-se na execução de ações de promoção de exportações de empresas brasileiras.

Por fim, cabe uma ressalva importante. De acordo com Cassiolato e Szapiro (2003), a mera ocorrência de produção voltada para a exportação não significa ampliação do grau de

\footnotetext{
${ }^{3}$ Para uma consulta mais detalhadas sobre as políticas públicas direcionadas aos APLs, sugere-se consultar Matos et al. (2016), Simonetti e Kamimura (2017), Turri (2017), Cassiolato e Lastres (2020), entre outros.
} 
territorialização dos arranjos. Além disso, Costa et al. (2017) destacam que a maioria das micro e pequenas empresas locais que se desenvolvem em função do efeito multiplicador da renda originada em APLs de base de exportação, geralmente tem níveis de capacitação tecnológica reduzidos e defasados em relação à fronteira tecnológica dos respectivos setores econômicos e às empresas exportadoras, assim como processos de aprendizado inovativo precários e limitados no seu escopo e escala.

\section{Metodologia}

Para que o objetivo proposto fosse atingido, a pesquisa seguiu um procedimento metodológico descritivo, o qual foi combinado com um levantamento de dados primários, sendo esse realizado por meio de um formulário estruturado.

Especificamente sobre o formulário aplicado nessa pesquisa, cabe destacar que ele foi embasado em dois estudos. O primeiro, conduzido por Carneiro, Bianchi e Gomes (2016), os pesquisadores analisaram 209 empresas brasileiras do setor manufatureiro, exportadoras ou não, e buscaram avaliar as percepções dos gestores sobre os benefícios e as barreiras relacionados à exportação. Além disso, os autores citados também investigaram sobre as capacidades que habilitavam as empresas pesquisadas a competirem no mercado externo. Já outro estudo, desenvolvido por Pereira et al. (2018), reuniu uma amostra com 14 empresas exportadoras localizadas no estado de Santa Catarina, com o intuito de verificar os fatores que influenciavam no ingresso das respectivas empresas no mercado internacional.

Dessa forma, para a presente pesquisa, o formulário foi organizado em três partes. $\mathrm{Na}$ primeira, buscou-se direcionar perguntas pertinentes à caracterização do perfil das empresas, dentre elas: localização, número de funcionários, tempo de atuação na atividade, se a empresa exportava, entre outras. Para as empresas exportadoras foram feitas outras sete perguntas, procurando descobrir há quanto tempo a empresa exportava, para quais locais destinavam seus produtos, quanto a exportação representava no faturamento da empresa, se havia departamento exclusivo constituído para tal finalidade, se algum gestor ou funcionário havia participado de alguma capacitação direcionada à exportação e se a empresa recebia incentivos fiscais por exportar. Por outro lado, caso a empresa respondesse que não exportava, eram feitas algumas perguntas para verificar se ela já havia considerado tal possibilidade, se havia buscado informação e capacitação e, se nessa busca encontrou dificuldades, além de investigar se já 
obteve alguma assistência de entidades de apoio para auxiliar e informar sobre o processo de exportação.

A última etapa do formulário foi composta por questões nas quais os entrevistados deveriam avaliar as alternativas em uma escala Likert variando de 1 a 5 , sendo 1 , caso discordassem totalmente, e 5, caso concordassem totalmente. Nessa etapa, todas as questões almejaram averiguar a percepção das empresas em relação aos benefícios advindos da exportação e com as dificuldades relacionadas a tal processo, como barreiras internas, externas, custos ocorridos de tal processo e, por último, os aspectos benéficos por participarem de um APL. Optou-se, também, visando ampliar a análise, desagregar as médias das respostas dessa etapa conforme a situação das empresas com relação à atividade exportadora (não exportadora, exporta esporadicamente e exportadora habitual), conforme já indicado na primeira etapa do formulário. Ressalta-se que todas as perguntas foram estruturadas de forma fechada.

Por fim, observa-se que o APL de Utensílios Domésticos em Alumínio do Sudoeste do Paraná conta atualmente com 31 empresas filiadas e ativas. Dessas, foram pesquisadas 24 empresas $^{4}$, sendo a amostra estratificada da seguinte forma: 13 empresas localizadas no município de Francisco Beltrão, 5 empresas em Marmeleiro, 2 empresas em Bom Sucesso do Sul, 2 empresas em Pato Branco, e 1 empresa nos municípios de Coronel Vivida e Nova Prata do Iguaçu, respectivamente. A pesquisa foi conduzida no período de setembro a novembro de 2019.

\section{Resultados e discussões}

Esse tópico encontra-se dividido em três seções, a saber: primeiramente será apresentada uma caracterização das empresas pesquisadas, além de já direcionar alguns apontamentos sobre as empresas exportadoras do APL de Utensílios Domésticos em Alumínio do Sudoeste do Paraná. Na sequência, a análise concentrar-se-á unicamente sobre as empresas não exportadoras. Na terceira e última seção, será demonstrada a percepção de todas as empresas do aglomerado, exportadoras ou não, sobre dimensões relativas à atividade exportadora e ao próprio APL.

\footnotetext{
${ }^{4}$ Devido ao tamanho reduzido da amostra que compõe o estudo ( $n \leq 30$ ), principalmente entre o número de componentes de representantes nos grupos estratificados (não exportador, exportador esporádico e exportador habitual), não foi possível um avanço estatístico para analisar as diferenças de médias.
} 
4.1 Caracterização do perfil das empresas participantes do APL e identificação de fatores ligados à exportação

Iniciando o esboço do panorama geral sobre o perfil relativo da amostra de empresas desse estudo, encontram-se, na tabela 1, dados relativos ao período de fundação das empresas relacionados aos seus respectivos portes. Para estabelecer uma padronização quanto ao porte, questionou-se quanto ao número de colaboradores que havia no quadro da empresa no momento da entrevista. Tal critério seguiu o padrão sugerido pelo SEBRAE (2018), a saber: indústria com até 19 colaboradores é considerada microempresa; de 20 a 99 colaboradores, considera-se empresa de pequeno porte; de 100 a 499 colaboradores é considerada como empresa de porte médio; e, acima de 500 colaboradores, empresa de grande porte.

Assim, conforme a tabela 1, verifica-se que, das empresas pesquisadas no APL de Utensílios Domésticos em Alumínio do Sudoeste do Paraná, 62,5\% são microempresas e 37,5\% enquadram-se como empresas de pequeno porte. Além disso, observa-se que as empresas mais antigas já apresentam porte de pequena empresa, ao passo que as empresas mais recentes no mercado ainda ostentam um porte de microempresa. Segundo o critério adotado, nenhuma empresa participante da pesquisa foi classificada como de porte médio ou grande. Contudo, isso reforça a caracterização estrutural já indicada por Marini et al. (2012) na constituição de um APL, isto é, que o APL é uma aglomeração setorial formada, basicamente, por pequenas e médias empresas.

Tabela 1 - Ano de fundação e o respectivo porte das empresas entrevistadas do APL de Utensílios Domésticos em Alumínio do Sudoeste do Paraná - 2019

\begin{tabular}{c|c|c|c}
\hline \multicolumn{2}{c|}{ Ano de fundação da empresa } & \multicolumn{2}{c}{ Porte da empresa (em \%) } \\
\hline Período & $($ em \%) & Microempresa & Pequeno \\
\hline 1990 a 1995 & 12,50 & 0,00 & 100,00 \\
\hline 1996 a 2001 & 25,00 & 33,33 & 66,67 \\
\hline 2002 a 2007 & 33,33 & 87,50 & 12,50 \\
\hline 2008 a 2013 & 25,00 & 83,33 & 16,67 \\
\hline 2014 até 2019 & 4,17 & 100,00 & 0,00 \\
\hline Total & 100,00 & 62,50 & 37,50 \\
\hline
\end{tabular}

Fonte: Elaborada pelos autores, 2020.

A seguir, buscou-se identificar quantas empresas participantes do APL estavam exportando, com o objetivo, também, de segmentar a pesquisa, possibilitando, assim, direcionar 
as perguntas adequadas às empresas exportadoras e não exportadoras. O resultado pode ser observado na tabela 2.

De acordo com o resultado da tabela 2, constata-se que 8,33\% empresas exportam, 4,17\% não exportam atualmente, mas já exportaram em algum momento, e 87,5\% não exportam. Além disso, destaca-se o fato de que, das empresas que responderam exportar ou já ter exportado em algum momento, nenhuma é microempresa. De posse desse resultado, algumas perguntas foram direcionadas somente às empresas exportadoras, as quais serão descritas a seguir.

Tabela 2 - Atuação no mercado externo, conforme o porte das empresas entrevistadas do APL de Utensílios Domésticos em Alumínio do Sudoeste do Paraná - 2019

\begin{tabular}{l|c|c|c}
\hline \multirow{2}{*}{ Sua empresa exporta? } & \multicolumn{2}{|c|}{ Porte da empresa (em \%) } & \multirow{2}{*}{$\begin{array}{c}\text { Total } \\
\text { (em \%) }\end{array}$} \\
\cline { 2 - 3 } & Microempresa & Pequeno & 87,50 \\
\hline Não & 100,00 & 66,67 & 4,17 \\
\hline Não, mas já exportou & 0,00 & 11,11 & 8,33 \\
\hline
\end{tabular}

Fonte: Elaborada pelos autores, 2020.

Com o propósito de identificar a demanda proveniente do exterior pelos produtos dessas empresas, perguntou-se quais produtos eram comercializados nas exportações, obtendo-se como as principais respostas: jogos de assadeiras, formas de assar pão, caçarolas, panelas de pressão, conjuntos de panelas em geral e pipoqueiras. Observa-se que, embora sejam itens diferentes, todos são produzidos a partir do alumínio e têm a mesma finalidade, que é a utilização para preparação de alimentos. Além disso, os produtos saem do Brasil na sua forma acabada, ou seja, sem a necessidade de novos processos ou finalização ao chegar ao destino.

Também foi questionado o tempo de atuação no mercado internacional. As respostas indicam que a prática de comercialização com outros países não é tão recente nas empresas do aglomerado, sendo que 33,33\% têm experiência com exportação entre 4 a 6 anos, 33,33\% de 7 a 9 anos, e 33,33\% já exportam há cerca de 10 anos ou mais.

Na sequência, procurou-se saber para quais países eram destinadas as exportações. 0 resultado foi que o Paraguai é o principal demandante dos produtos fabricados no APL de Utensílios Domésticos em Alumínio do Sudoeste do Paraná, pois todas as empresas exportadoras destinam parte de sua produção para esse país. Outras duas empresas responderam também exportar para o Uruguai, sendo que uma única empresa, além de exportar para os destinos supracitados, indicou que também exportar para os Estados Unidos. 
Outro ponto indagado foi o quanto as exportações representavam no total do faturamento anual. $\mathrm{O}$ resultado foi semelhante para todas as empresas exportadoras: de $1 \%$ a $15 \%$ do total faturado. Porém, cabe lembrar que tal faturamento está concentrado somente nas empresas de pequeno porte. Em continuidade, foi questionado se a empresa tem ou tinha departamento próprio para exportações ou se possui algum funcionário que desempenhasse função correlata, ou ainda, se já participou de capacitação na área de exportação (Tabela 3).

Tabela 3-Recursos humanos destinados à atividade exportadora nas empresas entrevistadas do APL de Utensílios Domésticos em Alumínio do Sudoeste do Paraná - 2019

\begin{tabular}{l|c|c}
\hline Empresa exportadora & \multicolumn{2}{|c}{ Respostas (em \%) } \\
\hline \multirow{2}{*}{$\begin{array}{l}\text { Possui departamento ou pessoa responsável pelas } \\
\text { exportações? }\end{array}$} & Sim & 33,33 \\
\cline { 2 - 3 } & Não & 66,67 \\
\cline { 2 - 3 } $\begin{array}{l}\text { O proprietário da empresa ou algum funcionário já participou } \\
\text { de alguma capacitação sobre exportação? }\end{array}$ & Sim & 0,00 \\
\cline { 2 - 3 } & Não & T3,33 \\
\hline
\end{tabular}

Fonte: Elaborada pelos autores, 2020.

A partir dos resultados apresentados na tabela 3, verifica-se que $66,67 \%$ das empresas que exportam não possuem departamento próprio ou pessoa responsável para essa atividade, resultado já esperado, dado que $62,5 \%$ das empresas pesquisadas são microempresas. Tal perfil também se confirmou quando questionados se o proprietário da empresa ou colaboradores já haviam realizado alguma capacitação sobre exportação. Ou seja, para os respondentes, ter um departamento ou pessoa responsável para a atividade de exportação não foi um diferencial para inseri-los no mercado internacional.

Completando a primeira etapa da pesquisa, questionou-se aos participantes se a empresa recebia algum incentivo financeiro para exportar seus produtos, sejam tais benefícios, nacional ou mesmo internacional. Todas as empresas exportadoras afirmaram que não recebiam nenhum incentivo. Neste ponto, cabe destacar que há vigente no país um regime tributário com tratamento diferenciado voltado, exclusivamente, para fomentar as exportações pelas empresas nacionais. Conforme o Ministério da Economia (2020), impostos como IPI, PIS/PASEP, COFINS e ICMS não incidem sobre o faturamento das exportações. Há, também, o Regime Especial de Reintegração de Valores Tributários para as Empresas Exportadoras (Reintegra), cuja finalidade é retornar de forma integral ou parcial o resíduo tributário remanescente na cadeia de produção de produtos exportados (BRASIL, 2015). Além disso, têm-se o regime de drawback, o qual permite que ocorra importação de insumos para produção de bens com destinação para 
exportação sem o pagamento de tributos, “[...] desde que haja, após beneficiamento e posterior agregação de valor, exportação" (MINISTÉRIO DA ECONOMIA, 2020, p. 1). Quanto às microempresas e empresas de pequeno porte, o que é o caso das empresas pesquisadas no APL, além dos benefícios já apresentados, elas podem, se optantes, enquadrarem-se no regime tributário do Simples Nacional, o qual permite uma receita adicional decorrente da atividade exportadora no valor de até $\mathrm{R} \$ 4.800 .000,00^{5}$. Portanto, primeiramente, observa-se que existem benefícios concedidos às empresas que buscam o mercado exterior. Porém, em um segundo momento, nota-se que tais informações não tem chegado de forma adequada aos participantes do APL.

\subsection{Empresas não exportadoras participantes do APL}

O tópico anterior apresentou o perfil das empresas do APL de Utensílios Domésticos em Alumínio do Sudoeste do Paraná, no qual se verificou quais empresas estão inseridas na atividade exportadora, totalizando $12,50 \%$ das empresas que já atuaram ou atuam no mercado externo. Em continuidade, o objetivo desta seção é compreender as variáveis que acometem as demais empresas, ou seja, $87,50 \%$ das empresas que não exportam seus produtos.

Portanto, inicialmente, perguntou-se à essas empresas se elas já haviam considerado a possibilidade de exportar. Foi possível identificar, então, que 54,55\% das empresas que não exportam já consideraram essa hipótese em algum momento, enquanto 45,45\% não avaliam a possibilidade de exportar. Entre as empresas que consideram a exportação uma alternativa viável, encontram-se aquelas de pequeno porte, além de 33,33\% das microempresas. Sobre o último grupo referido, destaca-se, assim, que a maioria das microempresas ainda não conseguiu compreender e incluir em seus planos a possibilidade de usufruir dos benefícios advindos do mercado externo. Na tabela 4, é possível visualizar outras informações complementares.

Verifica-se, na tabela 4 , que, enquanto $71,43 \%$ das empresas de pequeno porte foram atrás de informações e orientações acerca do processo de exportação, $73,33 \%$ das microempresas não o fizeram. Entre as que buscaram informações, $68,18 \%$ responderam não ter encontrado dificuldades. No entanto, nesse ponto, desperta atenção o fato de que $57,14 \%$ das empresas de pequeno porte ter respondido que obtiveram alguma dificuldade nessa etapa.

\footnotetext{
${ }^{5}$ Para mais detalhes consultar a Constituição Federal de 1988, artigos 149, 153 e 155, além da Instrução Normativa da Receita Federal do Brasil, no 948, de 15 de junho de 2009.
} 
Tabela 4 - Busca de informações e apoio à atividade exportadora das empresas não exportadoras, de acordo com o porte, no APL de Utensílios Domésticos em Alumínio do Sudoeste do Paraná - 2019

\begin{tabular}{l|c|c|c|c}
\hline \multirow{2}{*}{ Empresas que não exportam } & \multirow{2}{*}{ Alternativas } & \multicolumn{2}{|c|}{ Porte da empresa (em \%) } & \multirow{2}{*}{$\begin{array}{c}\text { Total } \\
\text { (em \%) }\end{array}$} \\
\cline { 3 - 4 } & & Microempresa & Pequeno & (em \\
\hline $\begin{array}{l}\text { Buscou informação/orientação para } \\
\text { exportar? }\end{array}$ & Não & 73,33 & 28,57 & 59,09 \\
\cline { 2 - 4 } $\begin{array}{l}\text { Encontrou dificuldades ao realizar a } \\
\text { buscar de informações? }\end{array}$ & Não & 26,67 & 71,43 & 40,91 \\
\cline { 2 - 4 } & Sim & 20,00 & 42,86 & 68,18 \\
\hline Já teve apoio de entidades para que & Não & 100,00 & 100,00 & 100,00 \\
\cline { 2 - 4 } \\
\cline { 2 - 4 }
\end{tabular}

Fonte: Elaborada pelos autores, 2020.

Ademais, para melhor compreender as dificuldades de inserção no comércio internacional, também foi questionado se as empresas já tiveram algum apoio de entidades de fomento, instituições governamentais ou outras do gênero que, de forma direta ou indireta, contribuíssem para que a empresa pudesse exportar. $O$ intuito é entender se os fatores que influenciam essas empresas a não exportarem são internos, externos ou ambos. Destacou-se o fato de que todas as empresas não exportadoras pertencentes ao APL responderam que em nenhum momento conseguiram suporte de entidades apoio sobre a referida temática. Contudo, nesse ponto em específico, podem-se destacar alguns programas voltados exclusivamente para capacitação em exportação, à exemplo do Programa de Qualificação para Exportação (PEIEX), ofertado pela Apex-Brasil (2020).

Com base nessas informações, buscou-se um indício quanto à existência de demanda externa pelo produto dessas empresas, como, por exemplo, a ocorrência, mesmo que esporádica, de compras informais realizadas por países vizinhos, como Argentina ou Paraguai. Dessa forma, inquiriu-se às empresas entrevistadas se elas já possuíam clientes oriundos de tais localidades e que compravam informalmente seus produtos. O resultado mostrou que, aproximadamente, $36 \%$ das empresas não exportadoras acabam comercializando de maneira informal com clientes de outros países, sendo que, neste caso, são os clientes que procuram a empresa para adquirir o produto. Com isso, há um indício forte que existe um potencial de exportação que não está sendo devidamente explorado por essas empresas.

4.3 Percepção das empresas participantes do APL sobre as exportações

Prosseguindo-se com a investigação sobre os desafios das empresas do APL de Utensílios Domésticos em Alumínio do Sudoeste do Paraná de se inserirem no comércio exterior, 
fundamentado em Carneiro, Bianchi e Gomes (2016), questionou-se às empresas entrevistadas, exportadoras ou não, sobre quatro aspectos relativos à percepção das mesmas sobre as exportações. O resultado, apresentado na tabela 5 , está ordenado conforme a média total calculada de cada opção apresentada para apreciação dos entrevistados, cujas alternativas, os participantes deveriam responder na escala entre 1 até 5, conforme já mencionado nos procedimentos metodológicos.

O primeiro ponto abordado mensurou a percepção sobre os benefícios com a exportação. Nota-se uma concordância de todos os entrevistados sobre a existência de tais benefícios, pois a pontuação média geral das condições elencadas foi de 4,40, ou seja, os entrevistados concordam parcialmente ou totalmente sobre os benefícios provenientes das exportações. Como as três principais condições percebidas, foram listadas diversificação de mercados, reação à recessão interna da economia e o aumento da lucratividade. No entanto, deve-se recordar que foi verificado entre os participantes que as exportações estavam concentradas em apenas três países, sendo que tal volume não impactava no máximo $15 \%$ do faturamento de algumas empresas.

No segundo ponto, o principal elemento investigado foi quanto à percepção das barreiras internas à exportação. Com as respostas, pode-se observar que a opção que se apresenta como maior barreira nesse quesito foi à falta de conhecimento ou experiência na atividade de exportação. Entretanto, retomando a tabela 4, verificou-se que 59\% dos respondentes sequer haviam buscado informação sobre o assunto. Em seguida, destaca-se o apontamento que revela a decisão em manter o foco apenas no mercado interno, sendo que, nesse quesito, houve uma maior incidência das microempresas. E, como terceiro ponto, tem-se a falta de mão de obra qualificada para auxiliar na atividade exportadora, porém, sendo esse mais percebido pelas empresas exportadoras. Sobre esse último ponto, Schlemper, Marini e Bernartt (2016), analisando outros três APLs na mesma região, também identificaram a falta de profissionais qualificados como um ponto negativo para o desenvolvimento dos APLs pesquisados. Por fim, em média, as empresas não classificam pontos relacionados à produção e estoque como limitantes, o que pode ser um indicativo de que algumas dessas empresas estejam operando abaixo da capacidade produtiva (Tabela 5). 
Tabela 5 - Percepção das empresas entrevistadas no APL de Utensílios Domésticos em Alumínio do Sudoeste do Paraná em relação às exportações - 2019

\begin{tabular}{|c|c|c|c|c|}
\hline \multirow{2}{*}{ Percepção dos benefícios com a exportação } & \multicolumn{3}{|c|}{ Exporta? } & \multirow{2}{*}{$\begin{array}{l}\text { Média } \\
\text { Total }\end{array}$} \\
\hline & M1 & M2 & M3 & \\
\hline Diversificar mercados & 4,71 & 5,00 & 5,00 & 4,75 \\
\hline Reagir à recessão da economia brasileira & 4,57 & 5,00 & 5,00 & 4,63 \\
\hline Aumentar lucratividade & 4,57 & 4,00 & 5,00 & 4,38 \\
\hline Explorar economias de escala (aumentar a produção e diminuir custo) & 4,29 & 5,00 & 4,50 & 4,33 \\
\hline Utilizar capacidade ociosa de produção & 4,29 & 5,00 & 4,50 & 4,33 \\
\hline $\begin{array}{l}\text { Consagração da marca no mercado externo, reflete-se no mercado } \\
\text { interno }\end{array}$ & 3,86 & 2,00 & 4,00 & 4,29 \\
\hline Contornar limitações de mercado doméstico restrito & 4,05 & 4,00 & 4,50 & 4,08 \\
\hline Percepção das barreiras internas à exportação & M1 & $\mathrm{M} 2$ & M3 & MT \\
\hline Falta de conhecimento/experiência nessa atividade & 4,52 & 3,00 & 4,00 & 4,42 \\
\hline Foco apenas no mercado interno & 4,10 & 2,00 & 2,00 & 3,83 \\
\hline Mão de obra qualificada & 3,52 & 1,00 & 4,00 & 3,46 \\
\hline Falta de recursos financeiros & 3,48 & 4,00 & 1,50 & 3,33 \\
\hline Estoque de produtos insuficiente para expansão & 3,33 & 1,00 & 2,00 & 3,13 \\
\hline Percepção das barreiras externas à exportação & M1 & M2 & M3 & MT \\
\hline Falta de familiaridade com práticas de negócio no exterior & 4,33 & 2,00 & 4,50 & 4,25 \\
\hline Necessidades de preços muito baixos p/ conquistar mercado & 4,19 & 3,00 & 4,50 & 4,17 \\
\hline Dificuldades em encontrar distribuidor confiável no exterior & 3,76 & 2,00 & 5,00 & 3,79 \\
\hline Falta de apoio governamental no estímulo às exportações & 3,86 & 4,00 & 2,00 & 3,71 \\
\hline Instabilidade da taxa de câmbio & 3,57 & 4,00 & 5,00 & 3,71 \\
\hline O Impacto da crise financeira global & 3,76 & 2,00 & 3,50 & 3,67 \\
\hline Falta de entendimento dos aspectos culturais estrangeiros & 3,81 & 2,00 & 3,00 & 3,63 \\
\hline Barreiras legais e regulatórias no mercado de exportação & 3,75 & 5,00 & 2,50 & 3,54 \\
\hline Informações de mercado incorretas/insuficientes & 3,50 & 1,00 & 5,00 & 3,38 \\
\hline Dificuldades em receber pagamento por produtos exportados & 3,14 & 5,00 & 2,50 & 3,38 \\
\hline Barreiras com outro idioma & 3,05 & 1,00 & 4,00 & 3,04 \\
\hline Falta de demanda no exterior para os produtos & 2,86 & 1,00 & 2,00 & 2,71 \\
\hline Percepção das dificuldades advindas dos custos com exportação & M1 & $\mathrm{M} 2$ & M3 & MT \\
\hline Impostos e taxas governamentais brasileiras & 4,24 & 5,00 & 2,50 & 4,13 \\
\hline Documentos e procedimentos legais & 4,24 & 4,00 & 2,50 & 4,08 \\
\hline Exigências regulatórias (embalagem, rotulagem, etc.) & 3,95 & 3,00 & 5,00 & 4,00 \\
\hline Frete Internacional (aéreo, terrestre ou marítimo) & 3,95 & 3,00 & 3,50 & 3,88 \\
\hline Mão de obra no Brasil & 3,86 & 4,00 & 3,00 & 3,79 \\
\hline Impostos e taxas dos países importadores & 3,76 & 4,00 & 3,50 & 3,75 \\
\hline Financiamento para expansão da capacidade produtiva & 3,67 & 5,00 & 3,00 & 3,67 \\
\hline Seguros de exportação & 3,71 & 3,00 & 3,50 & 3,67 \\
\hline Matérias-primas & 3,33 & 3,00 & 2,50 & 3,25 \\
\hline
\end{tabular}

Nota: M1: Não é exportador; M2: Não exporta, mas já exportou; M3: Exportador

Fonte: Elaborada pelos autores, 2020. 
Perguntou-se, ainda, sobre a percepção das barreiras externas às exportações. Destacamse como as principais respostas obtidas acerca do assunto: falta de familiaridade com práticas de negócios no exterior; necessidade de ser mais agressivo no mercado, ofertando o produto com preços relativamente mais baixos que os concorrentes para conquistar mercado; e, dificuldades em encontrar um distribuidor confiável no exterior (Tabela 5).

Esperava-se nesse grupo de questões, conforme verificado por Carneiro, Bianchi e Gomes (2016), que fatores relacionados à falta de apoio governamental, taxa de câmbio e barreiras legais e regulatórias figurassem entre os mais relevantes. Mas, não foi esse o caso das empresas aqui entrevistadas, demonstrando, assim, as singularidades presentes nos diversos aglomerados produtivos.

Neste sentido, um adendo deve ser feito quanto à questão da taxa de câmbio. Segundo Krugman, Obstfeld e Melitz (2015), a taxa de câmbio tem um papel fundamental no comércio internacional, uma vez que permite a comparação entre os preços de mercadorias de um país para outro. Já para Silva, Freitas e Mattos (2016), a taxa de câmbio é uma das variáveis de mais impacto no mercado internacional, pois uma alteração na respectiva taxa pode alterar os valores dos bens domésticos em relação aos estrangeiros. Nota-se, porém, que as empresas exportadoras do APL de Utensílios Domésticos em Alumínio do Sudoeste do Paraná concordam plenamente com a importância dessa variável sobre a influência em suas exportações, enquanto as microempresas (não exportadoras) ficaram praticamente indiferentes à variável.

No quarto ponto, foi abordada a percepção das dificuldades advindas dos custos com exportação. Entre as alternativas para avaliação dos entrevistados, as que receberam maiores pontuações, indicando dificuldades de inserção no exterior, foram os impostos e taxas governamentais brasileiras, com a média de 4,13 , seguido da questão de documentação e procedimentos legais. Sobre a questão de impostos e taxas, já foi descrito anteriormente a existência de regimes tributários diferenciados voltados exclusivamente à atividade exportadora, sendo importante o domínio de tal informação por parte das empresas. Em relação à documentação e procedimentos legais para a atividade de exportação, há certa padronização nos documentos exigidos, podendo-se citar entre os principais: fatura comercial, fatura proforma, contrato de compra e venda, contrato de câmbio, nota fiscal, romaneio de embarque, conhecimento de embarque, certificado ou apólice de seguro, certificado de classificação para fins de fiscalização da exportação, registro de exportação, entre outros (FIEP, 2020).

Nesse ponto, pesa o resultado apresentado anteriormente na tabela 3, pois, caso as empresas tivessem departamento ou alguém treinado e capacitado para a atividade 
exportadora, certamente esse quesito seria mitigado e não exerceria uma influência tão negativa como a que foi verificada.

Por fim, levantou-se a questão sobre a percepção relacionada aos benefícios em participar do APL, além de investigar a percepção das empresas em relação ao arranjo produtivo, uma vez que o APL pode contribuir favoravelmente para muitos pontos levantados nessa pesquisa. Os resultados são apresentados na tabela 6, ressaltando-se que as respostas poderiam variar na escala entre 1 e 5, sendo que 5 corresponde ao valor mais positivo (Tabela 6).

Tabela 6 - Percepção das empresas entrevistadas com relação à participação no APL de Utensílios Domésticos em Alumínio do Sudoeste do Paraná - 2019

\begin{tabular}{l|c|c|c|c}
\hline \multirow{2}{*}{ Percepção dos benefícios ao participar do APL } & \multicolumn{3}{|c|}{ Exporta? } & \multirow{2}{*}{$\begin{array}{c}\text { Média } \\
\text { Total }\end{array}$} \\
\cline { 2 - 5 } & $\mathrm{M} 1$ & $\mathrm{M} 2$ & $\mathrm{M} 3$ & \\
\hline Acesso às instituições de apoio & 4,62 & 4,00 & 5,00 & 4,63 \\
\hline Acesso às informações inerentes à sua atividade & 4,29 & 4,00 & 4,50 & 4,29 \\
\hline Benefícios internos à empresa & 4,14 & 5,00 & 4,50 & 4,21 \\
\hline Benefícios através das parcerias firmadas via APL & 4,19 & 4,00 & 4,50 & 4,21 \\
\hline Troca de conhecimento em processos produtivos e de gestão & 4,10 & 5,00 & 4,50 & 4,17 \\
\hline Maior visibilidade da sua empresa & 4,14 & 3,00 & 4,00 & 4,08 \\
\hline Benefícios externos à empresa & 4,05 & 5,00 & 4,50 & 3,96 \\
\hline Maior visibilidade do seu produto & 3,71 & 3,00 & 4,00 & 3,67 \\
\hline Novos conhecimentos em processos produtivos e de gestão & 3,48 & 4,00 & 4,00 & 3,54 \\
\hline
\end{tabular}

Nota: M1: Não exportador; M2: Não exporta, mas já exportou; M3: Exportador.

Fonte: Elaborada pelos autores, 2020.

Logo, conforme apresentado na tabela 6, os entrevistados avaliaram de forma positiva a participação no APL, sendo que a pontuação média total entre os quesitos variou de 3,67 a 4,63, demonstrando, com isso, que eles concordam de forma parcial ou totalmente com a importância do aglomerado produtivo e dos respectivos benefícios em seus negócios. Deve-se observar que tal percepção positiva se manteve entre todos os grupos analisados: não exportadores, exportadores esporádicos e exportadores habituais.

Além disso, o acesso às instituições de apoio se destacou nas respostas entre os resultados positivos, o qual foi muito bem avaliado tanto entre as empresas exportadoras quanto naquelas não exportadoras. Todavia, pode estar ocorrendo alguma inconsistência no modo operacional na relação entre tais entidades e as empresas, pois essas últimas avaliaram que o APL não está sendo efetivo em proporcionar conhecimentos em novos processos produtivos e de gestão, o que, talvez em grande parte, possa ser direcionado justamente pelas instituições de 
apoio. Não obstante, em que pese o aspecto produtivo, tal fato é de extrema importância, pois, de acordo com Porter (1990, p. 75),

\begin{abstract}
os concorrentes eventualmente e inevitavelmente ultrapassarão qualquer empresa que parar de melhorar e inovar. Às vezes, as vantagens dos pioneiros, como relacionamento com clientes, economia de escala nas tecnologias existentes ou a lealdade dos canais de distribuição, são suficientes para permitir que uma empresa estagnada mantenha sua posição entrincheirada por anos ou décadas. Mais cedo ou mais tarde, porém, rivais mais dinâmicos encontrarão uma maneira de inovar em torno dessas vantagens ou criar uma maneira melhor ou mais barata de fazer as coisas.
\end{abstract}

Contudo, conforme a conceitualização de APL apresentada por Marini et al. (2012), podese considerar que, de modo geral, com base nos resultados apresentados, o APL de Utensílios Domésticos em Alumínio do Sudoeste do Paraná está logrando êxito em fornecer algumas vantagens aos seus integrantes. Todavia, de forma geral, mesmo o APL sendo considerado de muita importância para as empresas, conclui-se que ainda existem oportunidades que podem ser apropriadas pelas empresas que o integram, principalmente no que tange às exportações, pois, muitos benefícios advindos da atividade exportadora não estão sendo devidamente auferidos por todas as empresas.

\title{
5 Considerações finais
}

Esse trabalho objetivou estudar as empresas pertencentes ao APL de Utensílios Domésticos em Alumínio do Sudoeste do Paraná, visando identificar quais são os principais desafios e as percepções das referidas empresas sobre a atividade exportadora.

Verificou-se que o APL tem em sua composição, basicamente, microempresas e empresas de pequeno porte, sendo que apenas $8,33 \%$ das empresas são exportadoras. Além disso, os principais parceiros comerciais listados foram Paraguai, Uruguai e Estados Unidos. Entre as empresas que não exportam, a maioria nunca buscou informação sobre o comércio exterior, e, as que o fizeram, disseram ter encontrado dificuldade nessa busca.

Em geral, as empresas entrevistadas no respectivo aglomerado produtivo julgam reconhecer a importância da atividade exportadora. Na percepção delas, o comércio internacional auxilia na diversificação de mercados, aumenta a lucratividade e, ainda, é uma opção para reagir durante as recessões econômicas no mercado interno. Entretanto, foi comum a constatação que algumas barreiras têm dificultado o acesso ao mercado externo, sendo as principais: falta de conhecimento e experiência com exportação, além dos alegados custos e a documentação necessária para tal finalidade. 
Já quando inquiridas quanto à percepção dos benefícios em participar do APL, em média, as empresas possuem uma percepção positiva acerca dos benefícios gerados pelo aglomerado. Contudo, infere-se, com base nas empresas que compuseram a amostra dessa pesquisa, que existe uma lacuna interna na atuação do APL e que certamente demandará o envolvimento dos demais agentes de apoio ligados diretamente ao arranjo. Tal lacuna está assentada no propósito de nortear novas ações e, quem sabe, novos direcionamentos acerca da exportação, como exemplos, a melhoria de processos produtivos, na orientação técnica e formação organizacional e de gestão, ou mesmo a realização de acordos com novos parceiros comerciais no exterior, tudo isso preparando positivamente as empresas e contribuindo para que o amadurecimento delas torne possível a exportação. Assim, no futuro, talvez o APL possa reforçar o apoio aos seus integrantes e ajudá-los expandirem seus negócios, gerando mais empregos e renda e, além disso, propiciando novas oportunidades ligadas à atividade exportadora por toda a região que concentra o aglomerado produtivo.

\section{Referências}

AGÊNCIA DE DESENVOLVIMENTO REGIONAL DO SUDOESTE DO PARANÁ. Plano de Desenvolvimento Regional Integrado, 2015 - 2020. 2015. Disponível em: http://pdri.agenciasudoeste.org.br/downloads/1 Acesso em: 29 mai. 2020.

ALVES, L. R. Especialização produtiva e desenvolvimento econômico regional. In: PIACENTI, C.A.; LIMA, J. F.; EBERHARDT, P. H. C.; ALVES, L. R. (Orgs). Economia e desenvolvimento regional. Foz do Iguaçu: Parque Itaipu, 2016. p. 69-79.

AMARAL FILHO, J. A endogeneização no desenvolvimento econômico regional e local.

Planejamento e Políticas Públicas, n. 23, p. 261-286, 2001.

APEX-BRASIL. Programa de Qualificação para Exportação. 2020. Disponível em:

https://portal.apexbrasil.com.br/qualifique-sua-empresa-peiex/ Acesso em: 10 jun. 2020.

BECATTINI, G. Italian industrial districts: problems and perspectives. International Studies of Management \& Organization, v. 21, n. 1, p. 83-90, 1991.

BRASIL. Receita Federal do Brasil. Instrução Normativa RFB no 948, de 15 de junho de 2009.

Diário Oficial da União: seção 1, Brasília, DF, ano 146, p. 6 - 8, 16 jun. 2009.

BRASIL. Decreto no 8.415, de 27 de fevereiro de 2015. Disponível em:

http://www.planalto.gov.br/ccivil_03/_Ato2015-2018/2015/Decreto/D8415.htm Acesso em: 07 jul. 2020.

BRASIL. Constituição da República Federativa do Brasil: texto constitucional promulgado em 5 de outubro de 1988. Brasília: Senado Federal, 2016. Disponível em: https://www2.senado.leg.br/bdsf/bitstream/handle/id/518231/CF88_Livro_EC91_2016.pdf Acesso em: 27 mai. 2020. 
BRASIL. Ministério da Economia. Exportação e importação geral. 2019. Disponível em: http://comexstat.mdic.gov.br/pt/geral Acesso em: 9 mai. 2020.

BRASIL. Ministério da Economia. Desoneração das Exportações. 2020. Disponível em: https://www.gov.br/produtividade-e-comercio-exterior/pt-br/assuntos/comercioexterior/desoneracao-das-exportacoes Acesso em: 15 mai. 2020.

CARNEIRO, J.; BIANCHI, C.; GOMES, R. M. Exportações brasileiras: benefícios e obstáculos na percepção das empresas. Tecnologias de Administração e Contabilidade, v. 6, n. 1, pp. 22-38, 2016.

CASSIOLATO, J. E.; LASTRES, H. M. M. O foco em arranjos produtivos e inovativos locais de micro e pequenas empresas. In: LASTRES, H.M.M.; CASSIOLATO, J.E.; MACIEL, M.L. (org). Pequena Empresa: Cooperação e Desenvolvimento Local. Rio de Janeiro: Relume Dumará, 2003. p. 21- 34.

CASSIOLATO, J. E.; LASTRES, H. M. M. The framework of 'local productive and innovation systems' and its influence on STI policy in Brazil. Economics of Innovation and New Technology, v. 29, p. $784-798,2020$.

CASSIOLATO, J.E.; SZAPIRO M. Uma Caracterização de Arranjos Produtivos Locais de Micro e Pequenas Empresas. In: LASTRES, H.M.M.; CASSIOLATO, J.E.; MACIEL, M.L. (org). Pequena Empresa: Cooperação e Desenvolvimento Local. Rio de Janeiro: Relume Dumará, 2003.

CERETTA, G. F.; CUNHA, S. K.; ROCHA, A. C. Gestão sustentável na cadeia de suprimentos e desempenho inovador em processos: um estudo com empresas da indústria do alumínio do sudoeste do paraná. Revista Gestão Organizacional, v. 8, n. 3, p. 56 - 76, 2015.

CONFEDERAÇÃO NACIONAL DA INDÚSTRIA. Desempenho da indústria no mundo. Ano 3, n. 1, 2019. Disponível em: http://www.portaldaindustria.com.br/estatisticas/desempenho-daindustria-no-mundo/ Acesso em: 21 mai. 2020.

COSTA, O. M. E. APL's como Estratégia de Desenvolvimento: Uma Abordagem Teórica. Fortaleza: IPECE, 75 p., 2011.

COSTA, O. M. E. Políticas públicas e o desenvolvimento de arranjos produtivos locais em regiões periféricas. Revista Inclusão Social, v. 7 n. 2, p.30-47, 2014.

COSTA, F. A.; BRITTO, J. N. P.; AMARAL FILHO, J.; CAVALCANTI FILHO, P. F. Arranjos Produtivos Locais: estruturação, situação e dinâmica. In: MATOS, M. P. et al. (Orgs.). Arranjos produtivos locais: referencial, experiências e políticas em 20 anos da Redesist. Rio de Janeiro: E-Papers, 2017. p. $121-159$.

CUNHA, J. A. C.; TERRA, L. A. A. Diferenciando os clusters dos arranjos produtivos locais.

Ciências Sociais Aplicadas em Revista, v. 8, n. 15, p. 09-25, 2008.

DEBORTOLI, J. V. C.; BERNARDINO, C. F.; ARAUJO, U. P.; LOPES, D. P. T. Critical meta-study of local productive arrangements research. Revista Eletrônica de Administração, Porto Alegre, v.26, n.3, p. 709-738, 2020.

FEDERAÇÃO DAS INDÚSTRIAS DO PARANÁ. APL de Utensílios Domésticos e Produtos em Alumínio do Sudoeste do PR. 2019. Disponível em:

http://www.fiepr.org.br/sindicatos/sindimetalso/aplaluminiosudoeste/FreeComponent8097co ntent47507.shtml Acesso em: 14 ago. 2020. 
FEDERAÇÃO DAS INDÚSTRIAS DO PARANÁ. Documentos para exportação. 2020. Disponível em: http://www.fiepr.org.br/cinpr/servicoscin/orientacao-para-exportar/documentos-paraexportacao-1-24560-224335.shtml Acesso em: 07 jul. 2020.

GARCIA, R. Economias externas e vantagens competitivas dos produtores em sistemas locais de produção: as visões de Marshall, Krugman e Porter. Ensaios FEE, v. 27, n. 2, p. 301-324, 2006.

GOVERNO DO ESTADO DO PARANÁ. Arranjos Produtivos Locais geram 79,8 mil empregos no Paraná. 2015. Disponível em:

http://www.aen.pr.gov.br/modules/noticias/article.php?storyid=85262\&tit=Arranjos-

Produtivos-Locais-geram798-mil-empregos-no-Parana Acesso em: 13 mai. 2020

INSTITUTO PARANAENSE DE DESENVOLVIMENTO ECONÔMICO E SOCIAL. Arranjos produtivos

locais do Estado do Paraná: identificação, caracterização e construção de tipologia. Curitiba: Ipardes, 2006.

KRUGMAN, P. Increasing Returns and Economic Geography. Journal of Political Economy, v. 99, n. 3, p. $483-499,1991$.

KRUGMAN, P. Development, geography and economic theory. Cambridge: MIT, 1995.

KRUGMAN, P. What's new about the New Economic Geography? Oxford Review of Economic Policy, v. 14, n. 2, p. 7- 17, 1998.

KRUGMAN, P. R.; Obstfeld, M.; MELITZ, M. J. Economia Internacional. 10. ed. São Paulo: Pearson Education do Brasil, 2015.

LUCIANE, B.; CERETTA, G. F.; ROCHA, A. C. Potencial de desenvolvimento: um estudo do apl de alumínio na região sudoeste do Paraná. Revista Estudos do CEPE, n. 39, p. 157-180, 2014.

MARINI, M. J.; SILVA, C. L.; NASCIMENTO, D. E.; STRAUHS, F. R. Avaliação da contribuição de arranjos produtivos locais para o desenvolvimento local. Revista Bibliográfica de Geografía y Ciencias Sociales, v. XVII, n. 996, 2012.

MARINI, M. J.; SILVA, C. L. A mensuração do potencial interno de desenvolvimento de um Arranjo Produtivo Local: uma proposta de aplicação prática. Revista Brasileira de Gestão Urbana, v. 6, n. 2, p. 236-248, 2014.

MARSHALL, A. Princípios de Economia: tratado introdutório. São Paulo: Editora Nova Cultural, 1996.

MATOS, M. P.; BORIN, E.; CASSIOLATO, J. E.; ARRUDA, D. MARCELLINO, I. S. Brasil: uma década de políticas para arranjos produtivos locais e sua evolução. Revista Pymes, Innovación y Desarrollo, v. 4, n. 1, p. 11-36, 2016.

MATOS, M. P.; CASSIOLATO, J. E.; PEIXOTO, F. O referencial conceitual e metodológico para a análise de Arranjos Produtivos Locais. In: MATOS, M. P. et al. (Orgs.). Arranjos produtivos locais: referencial, experiências e políticas em 20 anos da Redesist. Rio de Janeiro: E-Papers, 2017. p. $61-90$.

MATTEI, T. S.; MORAES, M. L.; BEZERRA, F. M. Os arranjos produtivos locais (APLs) de software no Paraná: uma análise pela ótica do desenvolvimento regional. Economia \& Região, v.5, n.1, p125-148, 2017.

PEGORARO, A. Francisco Beltrão, o berço das indústrias de panela no Paraná. Jornal de Beltrão, Francisco Beltrão, 12 set. 2019. Disponível em:

https://www.jornaldebeltrao.com.br/noticia/289375/francisco-beltrao-o-berco-das-industriasde-panela-no-parana Acesso em: 18 mai. 2020. 
PEREIRA, J .R.; ZILLI, J. C.; VIEIRA, A. C. P.; VOLPATO, D. Internacionalização empresarial: fatores determinantes para a tomada de decisão. Brazilian Journal of Development, v. 4, n. 2, p. 462471, 2018.

POLETTO, Jéssica Ramos. Tomada de decisão sobre investimentos: estudo multicasos em PMES do APL do alumínio do sudoeste do Paraná. 2017. 34 f. Trabalho de Conclusão de Curso (Especialização) - Universidade Tecnológica Federal do Paraná, Pato Branco, 2017.

PORTER, M. E. The competitive advantage of nations. Harvard Business Review, n. 2, p. 73-93, 1990.

PORTER, M. E. Clusters and the economics of competition. Harvard Business Review, nov-dec, Cambridge, p. 75-90, 1998.

SANTOS, G. A. G.; DINIZ, E. J.;BARBOSA, E. K. Aglomerações, arranjos produtivos locais e vantagens competitivas locacionais. Revista do BNDES, RIO DE JANEIRO, v. 11, n. 22, p. 151179, 2004.

SCHLEMPER, A. L.; MARINI, M. J.; BERNARTT, M. L. Arranjos produtivos locais e desenvolvimento regional: diagnóstico dos APLs da região Sudoeste do Paraná. Redes, v. 21, no 1, p. 36-55, jan./abr. 2016.

SCHMITZ, H.; NADVI, K. Clustering and Industrialization: introduction. World Development, v. 27, n. 9, p. 1503-1514, 1999.

SILVA, F. A.; FREITAS, C. O.; MATTOS, L. B. Volatilidade da taxa de câmbio e seus efeitos sobre o fluxo de comércio dos países da América do Sul. Revista de Economia Contemporânea, v. 20, n. 2, p. 229-249, 2016.

SIMONETTI, E. R. S.; KAMIMURA, Q. P. As políticas públicas direcionadas ao desenvolvimento de arranjos produtivos locais. In: OLIVEIRA, C. W. A, et al. (Orgs.). Arranjos produtivos locais e desenvolvimento. Rio de Janeiro: Ipea, 2017. p. $21-35$.

SUZIGAN, W.; FURTADO, J.; GARCIA, R.; SAMPAIO, S. Clusters ou Sistemas Locais de Produção: mapeamento, tipologia e sugestões de políticas. Revista de Economia Política, v.24, n.4, p. 548570, 2004.

SUZIGAN, W. Identificação, mapeamento e caracterização estrutural de arranjos produtivos locais no Brasil. 2006. 59 p. Disponível em:

http://www3.eco.unicamp.br/neit/images/destaque/Suzigan_2006_Mapeamento_Identificaca o_e_Caracterizacao_Estrutural_de_APL_no_Brasil.pdf Acesso em: 24 mai. 2020.

TATSCH, A. L.; BOTELHO, M. R. A.; MATOS, M. P. Arranjos produtivos locais como instrumento de promoção do desenvolvimento local e regional: as experiências do Sul e Sudeste. In: MATOS, M. P. et al. (Orgs.). Arranjos produtivos locais: referencial, experiências e políticas em 20 anos da Redesist. Rio de Janeiro: E-Papers, 2017. p. 121 - 159. p. 371 - 390.

TORRE, A.; ZIMMERMANN, J. B. Des clusters aux écosystèmes industriels locaux. Revue d'économie industrielle, v. 152, p. 13-38, 2015.

TURRI, T. Análise da política pública de arranjos produtivos locais no brasil. In: OLIVEIRA, C. W. A, et al. (Orgs.). Arranjos produtivos locais e desenvolvimento. Rio de Janeiro: Ipea, 2017. p. 53 -64 .

VASCO, A. P. D., et al. A gestão da inovação e o desenvolvimento de produtos em empresas de artefatos de alumínio no sudoeste do Paraná: ações para a sustentabilidade. Gestão Industrial, v. 10, n. 3, p. 494-513, 2014. 
VIEIRA, E. L.; COSTA, S. E. G. ; LIMA, E. P. . Avaliação qualitativa da utilização de práticas do lean manufacturing: estudo de caso em uma indústria de utensílios domésticos em alumínio e ferro fundido que não possui um sistema lean estruturado. Journal of Lean Systems, v. 3, p. 90-109, 2018.

VIGNANDI, R. S.; CAMPOS, A. C.; PARRÉ, J. L. Arranjos Produtivos Locais (APLs) confeccionistas e desenvolvimento socioeconômico no Estado do Paraná: uma análise multivariada. Ensaios FEE, v. 34, n. 2, 2013.

WILLERS, E. M. Estratégia de desenvolvimento econômico: do regional ao local. In: PIANCENTI, C.A.; LIMA, J. F.; EBERHARDT, P. H. C.; ALVES, L. R. (Orgs). Economia e desenvolvimento regional. Foz do Iguaçu: Parque Itaipu, 2016. p. 142-165. 